\title{
Viado Não, Canibal: masculinidade, sexualidade e produção de cidade na experiência do homoerotismo em João Pessoa - PB
}

\author{
I'm Not Fag, I'm Cannibal: masculinities, sexuality and city production in \\ homoerotic experience in João Pessoa, Paraíba
}
Maricón No, Caníbal: masculinidad, sexualidad y producción de la ciudad en la experiencia del homoerotismo en João Pessoa, Paraíba

\author{
Tiago de Lima Oliveira \\ Universidade Federal da Paraíba - Brasil \\ petraios@hotmail.com
}

\section{Resumo}

$\mathrm{O}$ artigo discute estratégias de posicionamento e atribuição de identidades em um cinema pornô no centro da capital paraibana a partir de narrativas de quatro interlocutores. As performances e posições assumidas no pornô buscam (re)afirmar e encenar modelos de masculinidade desejáveis a partir das demandas das interações ali estabelecidas, e nesse ínterim constantemente entram em embate com categorias identitárias já estabelecidas por políticas de visibilidade LGBT, desestabilizando-as de sua fixidez, alargando-as ou negando-as.

Palavras-Chave: Masculinidade; Identidades; Homossociabilidade.

\begin{abstract}
This article discusses positioning strategies and allocation of identities in a porn theater in the city of João Pessoa, Brazil, according to the narratives from four speakers. The performances and positions taken on in the theater seek to (re)affirm and enact desirable models of masculinity from the demands of the interactions established there, and constantly come into confrontation with identity categories established by homosexual visibility policies, disrupting them from the fixity they had assumed, extending them or denying them.
\end{abstract}

Keywords: Masculinities; Identities; Homosociabilities.

\section{Resumen}

Este artículo discute estrategias de posicionamento y atribución de identidades en un cine porno en el centro de la ciudad de João Pessoa, Brasil, a partir de las narrativas de cuatro interlocutores. Las performances y posiciones asumidas en el porno pretenden (re)afirmar y representar modelos de masculinidad deseables a partir de las demandas de las interacciones que se establecen en estos espacios y que constantemente se confrontan con las categorías identitarias establecidas por las políticas de visibilidad LGBT, desestabilizando su rigidez, extendiéndolas o negándolas.

Palabras-Clave: Masculinidad; Identidades; Homosociabilidad. 


\section{Introdução}

Tarde quente de verão na capital paraibana. A temperatura deve estar na média dos $32^{\circ} \mathrm{C}$ quando chego a pequena porta que dá acesso a um corredor com três cabines ladeadas à esquerda, uma pia à direita, dois mictórios ao fundo e muita lama entre a entrada e o fim. Estou no estacionamento do supermercado Hiper Bompreço, região do Parque Sólon de Lucena, em João Pessoa. Observo o entorno e vejo à direita um homem de ares balzaquianos e pele escura, escorado em um telefone público a pouco mais de 50 metros de distância. Entro no banheiro mal cheiroso, quente e pouco iluminado. Das três cabines uma se encontra ocupada, assim como ambos os mictórios. Entro numa das cabines e permaneço lá tentando clandestinamente depreender os segredos silenciosos daquele universo, o que se traduz em um esforço vão. Resolvo, então, sair e, já na pia, enquanto lavo as mãos, vejo sair de outra cabine um jovem magro com roupas coloridas e, poucos instantes depois, da mesma cabine, outro senhor mais velho vestindo bermuda e camiseta. Este último aproxima-se da pia onde estou, me olha alguns instantes, e em seguida sai do banheiro. Encontro-o depois próximo ao homem que anteriormente havia visto no telefone; pareciam conversar. Viro de costas e percebo os rapazes no mictório ao fundo se aproximarem um do outro.

A situação apresentada acima poderia passar despercebida ou inusitada para um usuário comum dos banheiros públicos masculinos em várias cidades. Todavia, um olhar mais atento aponta para existência de um circuito paralelo de atividades e usos destes espaços que se caracterizam por modos distintos de construção corporal e espacial, um universo conformado por códigos e valores específicos, formas de agir e relacionar-se. Esse circuito paralelo é o que se chama no contexto nativo de 'pegação', tendo também outros termos sinônimos, a exemplo de 'caça', ou cruising. Neste artigo, pretendo estabelecer algumas reflexões etnográficas a partir da pesquisa de campo desenvolvida entre frequentadores de cinemas pornôs da região do centro da capital paraibana, João Pessoa. Com o objetivo de cartografar e compreender os processos de classificação e construção/ atribuição de identidades em tais espaços, a pesquisa foi desenvolvida entre os anos de 2012 e 2013 em três cinemas pornôs de frequência majoritariamente masculina e, também, em espaços virtuais destinados a encontros entre homens, onde o tema da pegação era contemplado.

Interessa-nos, aqui, estabelecer uma reflexão localizada no duplo campo da antropologia urbana e estudos de gênero e sexualidade, a partir de uma noção processual de estudo da cidade, noção essa que se interessa em pensar a cidade como mutabilidade e transformação (AGIER, 2011; HUBBARD, 2012). Essa perspectiva possibilita o desenvolvimento de ferramentas metodológicas e analíticas que nos parece ser as mais adequadas para melhor entendimento das relações entre as pessoas e os lugares que (re/des)territorializam em suas práticas sociais e culturais.

Pegação é o termo adotado na capital paraibana para referir-se ao jogo de busca por trocas eróticas e sexuais - geralmente efêmeras - realizadas, potencialmente, entre homens, não envolvendo nenhuma expectativa de ganho financeiro (a exemplo da prostituição) ou implicando um envolvimento afetivo. O termo, ainda, pode indicar os locais onde tais práticas acontecem, sejam eles privados (quando construídos para tais fins), ou públicos, a exemplo de banheiros públicos, bares, cinemas pornôs, entre outros. Tais locais são perpassados por um processo de 
ressignificação e são transformados pelos usos dados pelos sujeitos. Além disso, a pegação estende-se de forma nevrálgica entre diversos espaços, borrando qualquer tentativa de classificação ortodoxa que determine limites entre público, privado, doméstico, online, offline ou profano.

Em outros contextos geográficos é possível falar, também, em 'caça' e 'cruising', trottoir e yiro; outra possibilidade é de adequar o nome da prática ao local onde acontece, de onde surgem, por exemplo, termos como cinemão e banheirão para referir-se à pegação em banheiros e cinemas pornôs, respectivamente. O termo genérico para referir-se aos locais é 'ponto de pegação'.

Os sujeitos que participam dos circuitos de pegação são caracterizados pela heterogeneidade em termos de condição social, classe, ocupação, e performances de gênero. Como sugere Raewyn Connell (2002), a produção de masculinidades está articulada a estes diversos marcadores sociais da diferença e estabelecem, também, formas distintas de relacionar-se com o espaço e construir lugares. Os modos de produção de lugares condicionam a participação de certos sujeitos e também estão relacionadas à produção de certos estilos e performances de gênero; em outras palavras, tais lugares produzem determinadas performances ao mesmo tempo em que são produzidos por estas.

A partir das narrativas de quatro interlocutores, Bruno, Francisco, Neto e Otávio $^{1}$, nos interessa problematizar as tensões estabelecidas entre dispositivos classificatórios e a reinvenção dos mesmos, a partir de um cinema pornô inserido no circuito de trocas eróticas e sexuais entre homossexuais masculinos na capital paraibana.

A natureza das relações construídas no cinema encontram-se em uma zona intersticial entre aquilo que Gaspar Neto
(2011) chama de 'coeficiente de anonimato' e a constante análise da conduta e performance alheias. Nestes espaços, a masculinidade é um capital importante que orienta as possibilidades de sucesso nas interações estabelecidas entre os sujeitos. Estabelece-se, então, entre os sujeitos uma espécie de contínuo balizado por estratégias de classificação de si e dos outros, que têm como propósito aproximar-se o máximo possível de um ponto extremo desejável e afastar-se de outro. Essas estratégias são evidenciadas pelas falas e, eventualmente, conduta dos frequentadores, que aqui estão simbolicamente apresentadas nas falas de quatro interlocutores com os quais estive mais próximo durante o desenvolvimento da pesquisa. As narrativas de Otávio, Francisco, Bruno e Neto não têm qualquer propósito 'estatístico', ou seja, não visam apresentar a totalidade proporcional da conduta e performances masculinas nos cinemas, antes, pelo contrário, apontam para possibilidades de vivência da sexualidade em tais espaços. Assim, aproximamo-nos de Claudia Fonseca ao afirmar que:

a força da etnografia está na sua capacidade de contar histórias. As histórias são escolhidas, apesar de nunca serem 'típicas', são - quando exploradas em toda sua especificidade - sempre reveladoras. Ainda mais, contar histórias é uma forma de transmitir algo do clima da revelação entre pesquisador e pesquisados, clima esse que é parte integrante dos "dados" (FONSECA, 2005, p. 263).

A etnografia, assim acreditamos, exige um olhar mais atencioso sobre os pequenos processos constitutivos que orientam as micropolíticas das relações entre pessoas. Perceber tais processos implica 
potencialmente no estabelecimento de manobras metodológicas, alternando o plano geral e os pequenos enquadramentos. Em todo caso, além da obstinação do etnógrafo em inserir na composição e sua análise tantos elementos externos e internos quanto sejam possíveis, há os limites daquilo que é permitido ver, ouvir, viver.

\section{Gênero, Sexualidade e Produção de Cidades: reflexões iniciais}

Em seu aspecto epistemológico, neste trabalho busco, através de uma abordagem etnográfica, compreender a relação entre identificação/performance de gênero e a construção de territorialidades na cidade a partir de espaços de trocas eróticas e sexuais estabelecidas majoritariamente por homens na cidade de João Pessoa. Desde meados do século $\mathrm{XX}$, as práticas homoeróticas vêm compondo parte do repertório de pesquisa por parte das Ciências Sociais; todavia, uma leitura mais atenta dos clássicos e trabalhos de referência na área sinalizam algumas preocupações específicas, a exemplo da sociabilidade (BARBOSA DA SILVA, 2003 [1959]), da saúde, da emergência de movimentos políticos homossexuais com a epidemia da AIDS (FRY, 1982; MACRAE, 1990; PARKER, 1991; FACCHINI, 2005), a partir da década de 1980. Nesse aspecto, as preocupações com a construção de performances de gênero, bem como as relações com o espaço, têm sido subsumidas às temáticas relacionadas à promoção da saúde e às tensões políticas frente a contextos e atores sociais emergentes. Tais trabalhos, apesar de sua importância e relevância para estabelecimento de um campo de estudos sobre sexualidade no Brasil, estão localizados geograficamente no espaço das grandes metrópoles do sul e sudeste e ignorando a diversidade de práticas e realidades sociais e culturais de outras regiões ${ }^{2}$.
No contexto das práticas eróticas e sexuais contemporâneas, o antropólogo Luis Fernando Dias Duarte (2004) sinaliza para um processo de intensa negociação no mundo ocidental em torno da "normalização" de práticas abjetas, rejeitadas, em geral descomprometidas com a reprodução, a exemplo da masturbação, prostituição, do homoerotismo, incluindo-se aqui, também, o que definimos como 'pegação'. Ainda no contexto brasileiro, uma perspectiva biográfica e etnográfica apresentada em trabalhos como os de Perlongher (2008), Trevisan (2000) e Barbosa da Silva (2003), que evidenciam uma intensa relação entre a pegação como forma de sociabilidade clandestina e dissidente e a posterior erupção de um movimento homossexual pautado em um processo de higienização das condutas eróticas e sexuais, que, mais uma vez, contribuiu para a ilegitimidade da pegação como espaço e forma de sociabilidade. Esse processo está relacionado, por um lado, à eclosão da epidemia da AIDS e sua associação imediata com o público homossexual, e por outro, à criação de espaços que propiciassem encontros que ignoravam as normativas do intenso processo de negociação entre movimentos sociais e Estado que se desenvolvia no momento. Esse processo de constituições do que poderia ser chamado de 'regiões morais', como sugeriria Robert Parker (1973), foi estudado no Brasil por Nestor Perlongher (2008), que em sua etnografia sobre o universo da prostituição, no centro de São Paulo, chega a anunciar as intricadas relações entre a produção e territorialização dos espaços em seu uso e a construção de performances de gênero, que têm como objetivo manter determinadas formas de sociabilidade, baseadas, também, nas trocas sexuais, neste caso, entre michês e clientes.

Essa mesma percepção das relações entre gênero, sexualidade e a produção do espaço 
pode ser percebida já em Foucault (1999) e sua arqueologia da sexualidade. Segundo o autor, a construção de uma episteme que estaria no substrato e fundação do pensamento moderno ocidental localizado no século XVIII, período muito próximo à emergência da noção moderna de cidade, a partir do contexto hegemônico europeu, em lugares como França e Alemanha do século XIX. A projeção de cidades em torno de ruas, esquinas, sistemas de esgotos, sanatórios, hospitais, áreas residenciais e comerciais, escolas, enfim, coaduna com um processo de adestramento de corpos e da conduta sexual através de intervenções por parte da família, de instituições de saúde física e mental, da escola, e da própria divisão do trabalho, registrando, assim, lugares adequados para homens e para mulheres. A partir de uma perspectiva biopolítica, é preciso considerar, ainda, que esse processo está não apenas na relação do Estado como gerenciador da vida, mas também nos próprios códigos sociais e culturais internalizados e tomados como se fossem naturais, códigos que, ao mesmo tempo em que constroem os lugares onde seres humanos habitam, são construídos por esses mesmos humanos.

Aqui, através de uma reflexão sobre os usos do espaço e a construção de territorialidades, me interessa particularmente pensar as relações que estas práticas estabelecem com a construção de performances de gênero, em especial, de masculinidades. Como sugere a professora Fraya Frehse (2009), a partir de uma percepção do espaço como mediador das relações humanas, é possível entrever a noção de 'usos' não apenas como a copresença física e social das pessoas ocupando o solo, mas, principalmente, pela reiteração de comportamentos corporais e formas de sociabilidade que esse espaço possibilita. Nessa perspectiva, o espaço é visto não apenas como matéria construída (o espaço projetado em si), mas como substância sobre a qual se pode intervir através das possibilidades de interação e das situações que se desenvolvem nele.

Esses comportamentos corporais, a que se referiu Frehse, abrem espaço para refletir sobre a construção de performances de masculinidades no universo da pegação enquanto fenômeno social. A partir de Connell (2002), a masculinidade é entendida aqui como uma prática mediada pelo corpo, um enunciado performativo nos termos de Butler (2003). Para a autora, a masculinidade é encarada simultaneamente como um lugar nas relações de gênero, que se constitui como bem aponta Vale de Almeida (2000), não apenas em contextos de relações entre homens e mulheres, mas também em contextos de homossociabilidade (homens com homens, mulheres com mulheres, por exemplo), tendo em vista que o gênero não é um 'objeto', mas uma relação. Nas palavras da autora:

O gênero é uma forma pela qual a prática social é ordenada. No processo do gênero, a condução diária da vida é organizada em relação à produção de uma arena reprodutiva definida por estruturas corporais e processos de reprodução humana (...). O gênero é uma prática social que constantemente refere-se aos corpos e o que os corpos fazem, isto é, a prática social reduzida ao corpo. Tal reducionismo profundo apresenta na verdade o inverso da situação real: o gênero existe precisamente para marcar que a biologia não determina o social. (CONNEL, 2002, p. $71^{3}$ ).

O gênero constituiria, assim, não apenas 'identidades', categoria já em desuso, mas sim práticas variadas e multifacetadas que seriam 
entrecruzadas por discursos diversos. A masculinidade, assim como a feminilidade, não se apresenta sobre uma rubrica única. A produção da masculinidade é, assim, amparada pela coexistência de outros marcadores sociais da diferença que combinam-se na construção de significados para o "ser homem". Homens pobres, homens negros, homens gays, homens latinos, homens europeus não vivem a mesma experiência; pelo contrário, a produção se dá através de intensas disputas que constituem hierarquizações sociais em torno de performances de masculinidades hegemônicas e outras subalternas.

\section{'Papai' e seus Vizinhos}

Passa das 15 horas quando, finalmente, consigo chegar ao cinemão do Papai. Mormaço, carros, o ritmo frenético dos ônibus que descem o viaduto em direção ao antigo centro da cidade. 'Hora de louco', se costuma dizer. No entorno, algumas pessoas esperam a chegada de suas conduções, outros usam drogas na esquina paralela e, por fim, ali estou eu, parado frente àquele tapume de madeira prensada e pintada em preto que, de forma contraditória, busca a privacidade e a divisão entre o profano e o mais profano ainda. Ao lado da portinhola um cartaz mostra cenas de alguns filmes pornográficos todos heterossexuais, apesar da esmagadora frequência masculina buscando contato com outros homens. Enfim entro, converso alguns instantes com Ari, um dos proprietários; pergunto como havia passado o final de semana, do volume de clientes no domingo, sobre seu parceiro que já não vejo há algumas semanas. Após esses instantes de risadas e conversas ao léu, atravesso a segunda porta que divide a cabine de bilheteria e os espaços de exibição.

O Papai Cine Vídeo foi inaugurado em meados de 2006 e está localizado na Rua
Cardoso Vieira, atrás do Teatro Santa Rosa, um dos pontos históricos e mais conhecidos da cidade. Está localizado bem próximo ao Cine Sex América e também do Cine Aquarius, seus concorrentes.

O Cine Sex América se localiza na Praça Pedro Américo, ao lado do Teatro Santa Rosa e frente ao atual prédio onde funciona $o$ gabinete do prefeito e outras secretarias de Estado. Em se tratando de cinemas pornôs, é o mais antigo em funcionamento na cidade, estando em atividade desde o início de 2004 e é propriedade do grupo pernambucano Ferreira, que tem outros espaços de exibição do gênero na cidade do Recife. O processo de construção e manutenção social do cinema está relacionado a um processo adverso, de declínio dos cinemas de rua, algo semelhante ao registrado por Vale (2000) na cidade de Fortaleza. Em João Pessoa, o Cine Sex América se consolidou na contramão de um processo de falência registrado pelos três cinemas então em funcionamento na capital, o Rex, o Plaza e o Municipal. Enquanto o primeiro transferiu-se para um shopping, onde atualmente estão localizados todos os cinemas da capital, os demais foram 'decaindo', transformando-se primeiramente em salas de exibição de filmes eróticos e pornôs, para em seguida fecharem, dando espaço a outros tipos de empreendimento, notoriamente uma loja de calçados e uma Igreja protestante pentecostal. $\mathrm{O}$ ar de legalidade e regularidade no funcionamento do cinema é exposto com certo grau de distinção por seus proprietários, quando comparado aos demais cinemas em funcionamento: o Papai e o Aquarius.

Por fim, o Cine Sex Aquarius é a filial de um cinema pornô de mesmo nome que tem sede no interior do estado, na cidade de Campina Grande. O Aquarius é o mais recente dos cinemas, tendo sido fundado em 2008. Tem um público consideravelmente menor, em relação aos demais, todavia, é 
reconhecido como um dos melhores, justamente pela localização e discrição. Está localizado também na Avenida Cardoso Vieira, a poucos metros do Papai e uma rua atrás do América. No entanto, nada lhe chama a atenção dos caminhantes da rua. Uma fachada preta onde se desenha uma espécie de túnel negro com um pequeno aviso impresso em papel tamanho A4 indicando os valores e solicitando que os usuários não fiquem parados na porta. Em relação aos cartazes de sexo explícito colados na porta de entrada, tanto no Papai, quanto no América, o Aquarius é um equipamento modesto. Exibe dois filmes semanalmente, que são repetidos durante o dia em duas salas de exibição.

O Papai é o maior dos cinemas em funcionamento e tem um público tão grande quanto o América. Sua estrutura física é composta de cinco salas de exibição que reproduzem, simultaneamente e durante todo o dia, filmes pornográficos de classes diversas: heterossexuais, gays, bizarro, bissexuais e lésbicos. As superfícies de projeção variam de grandes telas a pequenos aparelhos de televisão ancorados nas paredes. Atualmente, constitui-se como uma rede administrada pelos senhores Carlos, Ari e Edvaldo e que conta com filiais nas capitais de outros dois estados, além da Paraíba: Rio Grande do Norte (inaugurado em 2010), Teresina (inaugurado em 2008). Diferente do América e outros cinemas onde ocorrem pegação, tais como o etnografado por Vale (2000), o Papai, assim como seu vizinho, o Aquarius, não é um cinema propriamente dito; trata-se, assim como os demais, de um antigo prédio de meados da década de 194050, como muitos na região. Seus compartimentos foram adaptados e transformados em salas de exibição como será posteriormente descrito.

Todos os cinemas estão localizados no bairro do Varadouro, região que nos últimos
10 anos tem sofrido um intenso processo de desvalorização imobiliária e degradação social. A pouco de uma década, a porção ocidental do bairro, que comporta a região próxima ao Porto do Capim e a região do baixo Centro comercial, compunha um dos espaços mais importantes e ativos da economia na capital agora. Já hoje, a alguns metros da Praça Antenor Navarro, bastião de resistência a este processo de decadência, vêse pequenos retratos em $3 \times 4$ que emolduram a decadência e arruinamento do lugar: antigos prédios com fachadas vencidas, caindo, pichadas; entre uma rua e outra se acumulam pedintes, batidas policiais diariamente fecham e abrem pontos de venda e consumo de entorpecentes como maconha e crack. Competindo com o desmoronamento comercial de produtos, na região vem se fortalecendo um ramo de prestação de serviços diversos segmentados em uma mesma direção: o comércio do/para o sexo. Nesse cenário aparecem espaços destinados não apenas à prostituição - entendida aqui não apenas como o envolvimento sexual em troca de dinheiro, mas também como um processo mais intenso de estabelecimento de trocas e negociações em torno de produtos e bens-simbólicos, como a proteção e segurança - em cabarés e na rua mesmo (de caráter esporádico), mas também pousadas, bares, cinemas pornôs e saunas.

O Papai acompanha e forma parte desse processo de declínio do comércio tradicional para reconfiguração da região como um espaço diferenciado de comércio, vinculado à busca de espaços de sociabilidade, muitas vezes marcados pelo segredo e pelo ganho rápido (financeiramente ou não). Todavia, o cinema circunscreve um tipo de sociabilidade diferenciada daquela que está presente na maior parte dos demais espaços que conformam essa mancha ${ }^{4}$ de lazer no centro antigo da cidade. A forma de interação buscada nesse espaço - e também nos outros 
dois cinemas da região e em algumas ruas já conhecidas pelos frequentadores - é o que se chama de 'pegação', um espaço para trocas eróticas ou sexuais sem qualquer esperança de ganho financeiro ou envolvimento afetivo inicial.

É preciso estar atento, ainda, para o caráter polissêmico do termo pegação. Pegação pode denotar não apenas a prática, mas também os espaços onde o encontro acontece. Assim, o cinema pode ser lido com uma "pegação", ainda que o termo seja geralmente atribuído àqueles espaços públicos, ou de livre acesso, onde não se cobra para entrar, tais como parques, banheiros públicos e algumas regiões da praia.

\section{Conhecendo o Papai}

Estou eu na entrada da porta quando de súbito aparece um senhor atrás de mim, procurando adentrar. Ele já havia pagado seu bilhete de entrada e esperava atravessar este umbral que separa, não sem vigilância, a bilheteria dos espaços de exibição. Viro-me e observo um sorriso gentil e afobado que se sobrepõe. Entrar por aquela porta estreita torna-se ainda mais difícil quando a abrimos, tendo em vista que a escuridão da porta soma-se à das placas de madeira que formam, juntas, uma espécie de barreira: são três pequenas cabines individuais onde os frequentadores podem assistir aos vídeos e se masturbarem em privativo. Ele aproxima-se para passar e, simultaneamente, esfrega seu corpo junto ao meu. Com alguma gentileza abro espaço para que ele adentre a sala e retiro-me, fechando a porta em seguida.

Como dito anteriormente, o Papai não é um 'cinema' em si, aos moldes de cinema a partir da indústria de entretenimento; trata-se de um antigo casarão da década de 1940 ou 50 que foi adaptado e, atualmente, conta com cinco cabines privativas e cinco espaços para exibição de filmes, além de uma pequena área aberta para fumantes. Façamos, então, um pequeno tour pelo espaço.

Após a bilheteria, que é recortada por um tapume que divide a rua da porta de entrada, está uma pequena portinhola em madeira que dá acesso às salas de exibição. Passando esse espaço chegamos, primeiramente, a um umbral de escuro intenso causado pela anteposição de três pequenas cabines, que ficam logo à frente da porta de entrada. Em seguida, pela esquerda, temos uma pequena área escura onde alguns rapazes costumam flertar, dispondo-se aleatoriamente pela parede de pouco menos de três metros de extensão. A partir dali, temos à frente as duas primeiras salas de exibição. À esquerda, cadeiras aleatórias postam-se frente a uma televisão posicionada sobre um orifício quadrado, desenhado na parede, que exibe filmes pornográficos de temática heterossexual; à direita um telão de mais ou menos quatro metros quadrados exibe filmes com temáticas heterossexuais ou lésbicas, sendo este último o mais frequente. Cada uma dessas duas primeiras salas dá acesso a outro espaço de exibição. A primeira, localizada à esquerda, dá espaço a uma pequena sala, menor que sua antecessora, onde são exibidos em uma pequena televisão sustentada por uma prateleira os filmes de temática bissexual e, eventualmente, aqueles protagonizados por travestis e menage à trois $^{5}$; na sala ao lado são exibidos em uma televisão de 21 polegadas os filmes de pornografia bizarra, tais como aqueles que envolvem animais, fetiches, sadomasoquismo, deficientes físicos, pessoas muito gordas ou anãs (cf. LEITE JUNIOR, 2006), esta sala abre espaço, ainda, para uma pequena saída que dá acesso à casa dos proprietários do cinema, um casal de migrantes que mora na cidade há aproximadamente nove anos. Há, ainda, um pequeno espaço para fumantes que separa 
esse primeiro conjunto de salas das salas de outro segmento do cinema, onde está localizando o underground e uma sala de exibição onde são projetados filmes pornôs de temática gay.

Os frequentadores dos cinemas costumam circular entre todos os espaços, localizandose, especialmente, em determinados lugares onde a concentração de pessoas disponíveis é maior, tais como a área de fumantes e as salas de exibição, para depois seguirem para as cabines ou outros espaços mais propícios ao sexo. Apesar de pouco frequente, também são recorrentes interações grupais, em geral, iniciadas através de momentos de voyeurismo de uma dupla onde o voyeur é convidado para participar das atividades através de gestos que convidam e intimam a participação, tais como o chamamento, os olhares, ou até mesmo a tomada da pessoa pelo braço até outro local, seja ali dentro mesmo, seja em outros locais fora das dependências do cinema.

Os cinemas estão incluídos nesse circuito maior da pegação, que conforma além dos próprios cinemas outros espaços como banheiros públicos, algumas regiões da praia, saunas e, eventualmente, alguns lugares com uma territorialidade marcadamente mais 'GLS', ou seja, segmentado a um público homossexual e simpatizantes, a exemplo de bares e boates. Os cinemas são uma das alternativas mais acessadas pelas pessoas que buscam fugir das ruas para encontrarem outras para atividades eróticas. $\mathrm{O}$ baixo preço cobrado pela entrada - R \$ 5,00 no Papai e no Aquarius e R\$ 7,00 no América - é um atrativo compensador, tendo em vista as diversas possibilidades que o lugar oferece; além de poder encontrar ali mesmo as pessoas, o namoro, flerte ou sexo podem ser desenvolvidos nas pequenas cabines de masturbação da entrada, em outras maiores localizadas no underground ou, até mesmo, em cantinhos escuros próximos à entrada, quando não mesmo nas áreas destinadas à exibição ${ }^{6}$.

É importante salientar, ainda, um aspecto importante do público que frequenta os cinemas. Em João Pessoa, com exceção das saunas que, devido ao alto preço cobrado pelos ingressos, os cinemas costumam agregar pessoas bastante heterogêneas e difusas, que não podem ser reunidas em um único estrato social, faixa etária, nível de escolaridade, ocupação profissional, tampouco em identidades sexuais. A exigência dos valores a serem cobrados, bem como a possibilidade de exigência de documentos, acaba freando a participação de menores - ainda que alguns consigam burlar isso - ou sujeitos de estratos sociais muito baixos (ainda que trabalhadores de rua, como pedintes e engraxates não sejam raros). Para estes últimos, o cinema acaba tornando-se, também, um espaço importante de trocas, pois no cinema têm a oportunidade de encontrar outros homens, em geral mais velhos, que dispõem-se a lhes dar dinheiro, comida ou outras modalidades de trocas restritas (LÉVI-STRAUSS, 2012 [1967]).

Ainda que a grande maioria dos frequentadores seja de trabalhadores e estudantes da região próxima, a paisagem é reinventada por pedintes e trabalhadores ambulantes, pequenos empresários, professores, aposentados, jovens de classe média e, até mesmo, mulheres que embaralham e borram qualquer ilusão de homogeneidade.

No plano das práticas e do jogo de conquista, a masculinidade engendrada pelos sujeitos é capital central na economia erótica da pegação. A masculinidade atua como moeda de troca que torna possível ter maior ou menor sucesso nas trocas estabelecidas principalmente nos espaços de menor prestígio, a exemplo da pegação de 'rua' e daquela em lugares que cobram entradas mais baratas. A 'masculinidade' a que me 
refiro, nesse caso, é modelo específico, em certo sentido 'hegemônico' (CONNELL, 2002); trata-se da performatização de certos gestos, trejeitos, condutas, enfim, 'técnicas corporais' (MAUSS, 2003) que veiculam uma imagem ampliada de um estereótipo 'macho', o que no sistema de classificação nativo é traduzido em categorias como machudo, pai de família, negão e cafuçu, que convivem com outras expressões subordinadas ou cúmplices a esse modelo hegemônico. Estabelece-se, assim, um paradoxo, tendo em vista que, ainda que o desejo seja homo-orientado, esse objeto de desejo deve ter uma aparência cosmética não homossexual, 'macho'. Nessas circunstâncias, observa-se uma tensão entre orientação sexual, práticas sexuais e identidades de gênero, que acabam por circunscrever variações desconcertantes naquilo que Butler (2003) chama de sistema sexo-gênero-desejo, ou seja, os mecanismos de produção de sujeitos que correlacionam através de uma ordem heteronormativa uma relação entre sexo biológico, gênero e orientação do desejo.

Não raramente, os homens envolvidos na prática de pegação rejeitam assumir uma identidade homossexual - o que não necessariamente implica em assumir outra identidade hetero ou bissexual - dentro dos contextos de troca em que estão inseridos. Em suas práticas esses sujeitos desenvolvem uma performance de gênero repetidamente encenada e afirmada como masculina, para todos os efeitos são 'homens', 'machos' e 'boys', ainda que tenham um desejo orientado por outros homens. Complementar a isso, têm práticas sexuais com homens e mulheres, podendo assumir posições variadas, a depender dos contratos estabelecidos no jogo da sedução. A particularidade dessas práticas reside, então, em não se desestabilizar, pelo menos problematizar uma política de visibilidade compulsória inaugurada pelo movimento LGBT no Brasil, que estabelece identidades que devem ser assumidas, sugere a coexistência de diversas formas, ou estratégias, de uso das identidades que se organizam em regime de fluidez, localizando as identidades nas situações de interação e espaços sociais pelos sujeitos no processo de negociação por direitos. A experiência de tais sujeitos.

\section{Viado não, Canibal}

Certo dia, em meados de setembro de 2013, em conversa com outros dois companheiros, Bruno relatava seu último encontro com um senhor mais velho, na faixa dos quarenta anos:

Bruno: Porra, fazia tempo que eu não comia um macho daqueles, pense... chega deu gosto. A cabine apertada $e$ o bicho tinha umas coxas, um peito bom de chupar $e$ uma bunda que pelo amor de deus... se tem outra igual eu quero comer também. Tinha até um pau gostoso; ainda dei umas chupadas nele porque ele tava pedindo e um macho daqueles a gente não pode rejeitar. Pesquisador: E como ele era? Bruno: acho que tinha uns 40, cabelo baixo, troncadinho, voz massa, todo macho. Do jeito que era capaz que eu desse pra ele [risos]

Neto: E tu agora tá dando também, é? Vai dar pra mim também?

Bruno: Sai daí, pô! Sou viado ${ }^{7}$ não.. [todos riem]

Pesquisador: E se não é viado é o que então?

Bruno: sou macho, né?! Viado não, sou canibal! [todos riem]

Eu posso até ser gay, mas não sou como essas bichinhas por aí. Não ando saltitante, não sou afeminado, 
bichinha, né? Não sou nem curto. Gosto de macho que curte, macho mesmo. Ontem no [bate-papo do site] Uol conheci um cara de Mandacaru; a gente abriu a webcam, era massa e tal,e marcou de se ver.. quando parei na praça pra ver tava uma bicha gorda, um viadinho assim, daí eu liguei pra ver se era ele mesmo e uma voz que parecia uma moça!... Ela já tinha me percebido e entrou no carro, mas não tinha como rolar... dei um perdido nele e devolvi pro mesmo lugar, dizendo que não rolava, que não estava bem...ainda ontem mesmo ele me ligou e eu não atendi. Sou macho e curto macho, não esses viadinhos aí. (Março/ 2013)

Ao negarem uma identidade/identificação como 'viadinhos', meus interlocutores não ignoram a possibilidade de virem a ser posicionados, ou até mesmo a posicionaremse enquanto homossexuais, mas rejeitam as imagens socialmente construídas em torno da homossexualidade enquanto encenação de um gênero feminino, ou que segue em direção a este. Para fugir a estas imagens, as estratégias de negação, ocultação e reinvenção são as mais comuns. Por ocultação entendo a possibilidade de uma vivência homoerótica em paralelo à uma identidade heterossexual; esse tipo de estratégia é constantemente apresentado a respeito dos 'pais de família' que, em geral, localizam-se num extremo desejável do contínuo de performances desenvolvidas no cinema. Certa vez, me comentou Otávio a respeito de um senhor, segundo ele, pastor em uma igreja protestante "diz que é crente e vem pra trepar com os machos... se a mulher soubesse". Por sua vez, a reinvenção inaugura uma estratégia de estabelecimento de identidades mais flexíveis, organizadas segundo os interesses dos indivíduos e suas performances, como se verá adiante.

Nas falas de Francisco e Bruno sobrepõem-se alguns aspectos já evidenciados, anteriormente, na fala de Otávio sobre os perfis de masculinidade desejáveis: o uso do corpo para movimentarse, a voz, o léxico e o jeito de falar, símbolos como roupas, cortes de cabelo, enfim, compõem uma performatividade estratégica que é acionada com o propósito de construir uma imagem desejada. Neto, um dos interlocutores mais jovens com quem venho desenvolvendo a pesquisa, apresenta alguns elementos que parece sugerir tal processo de 'performatividade localizada', se é que podemos chamar assim. Em conversa através do dispositivo de mensagens de uma rede social, ele comenta a respeito de si e dos outros colegas, em especial Bruno:

Assim, eu não me acho muito diferente deles, apesar deles serem mais velhos. A gente tem os mesmos gostos, as vezes fica com os mesmos caras e tal... mas eu acho que, sei lá, sou mais livre mesmo... tipo no cinema eu as vezes vou de farda, as vezes de bermuda e camisa como eles, outras vezes vou do jeito do pessoal da minha idade. Acho que sou mais livre que eles, ou sei lá...

Durante a pesquisa, também pude observar algo parecido entre outros frequentadores que encontrei em outros lugares onde desenvolvo a investigação, a exemplo de saunas e banheiros e boates. Assim, é possível sugerir que as performances são organizadas a partir das demandas de interação que cada espacialidade comporta; ainda que a masculinidade seja um capital importante em todas, acredito que há certos espaços mais exigentes, enquanto outros são mais 
maleáveis, aceitando algumas variações questionadoras, que se situam em regiões de fronteira, a exemplo das saunas, que eventualmente recebem travestis e drag queens para apresentações artísticas e que, logo em seguida, são incorporadas na dinâmica de sedução dos espaços e conseguem desenvolver alguns relacionamentos sem grandes dificuldades ${ }^{8}$.

Para meus interlocutores, as identidades sexuais que vivenciam (identidades no plural, porque constantemente são reordenadas a mercê das situações e interações que vivem) não têm a ver com as posições sexuais assumidas durante a transa em si, mas antes, a um conjunto variante de atos performativos (BUTLER, 2003) que compõem cadeias de inteligibilidade para o que pode ser entendido como masculino ou não. Seus corpos são "um conjunto de fronteiras, individuais e sociais, politicamente significadas e mantidas" (Ibdem, p. 59). Todavia, no jogo entre corpo, sexo, performance e identidades sexuais, nesse caso, é preciso ter em mente que tais encadeamentos são simultaneamente concebidos, num primeiro momento, como estabelecidos, naturais, fixos, imanentes, mas também podem ser flexibilizados de modo a aproximar-se o máximo possível de um extremo desejável: o macho.

Estabelece-se, assim, um contínuo entre possibilidades êmicas de classificação que se significam os jogos corporais performativos desde um extremo "machudo" até uma outra "travesti"9, como se observa no Quadro 01.

A identidade de machudo é reservada aos homens maduros, em geral casados, razão pela qual, eventualmente, são referidos como 'pais de família', todavia, nunca a vi aplicada a qualquer pessoa negra ou com aparência que pudesse denunciar o pertencimento a uma classe social muito baixa, como onde estão inseridos pedintes e moradores de rua. Para estes, existe como que uma estratégia de 'penalização', que por um lado fetichiza o corpo negro e o corpo proletário em identidades masculinas de negões e cafuçus, mas, por outro lado, reduz ou subordina seu valor de masculinidade a um modelo mais desejável, branco e burguês personificado no pai de família. Em seguida, se tem padrões aceitáveis, mas que se localizam na medida do possível como 'corpos regulares', que não estão num extremo de masculinidade idealizado, mas, que também não seguem em direção a outro. Esses corpos, geralmente, são lidos como discretos, desejados e desejáveis, na medida em que não denunciam trejeitos femininos, tampouco superevidenciam uma performance de masculinidade hiperbólica que dentro das interações do cinema é frequentemente questionada como 'enrustida'. Por fim, no ponto extremo aparecem performances pouco valorizadas, mas, ainda assim, utilizadas como forma de desqualificar as performances de possíveis concorrentes, e

Quadro 1: Contínuo de classificações êmicas em torno das performances masculinas

\begin{tabular}{|l|l|l|}
\hline MACHO & \multicolumn{2}{|c|}{ "VIADO" } \\
\hline \hline Negōes & \multicolumn{1}{|c|}{ Militar (milico) } \\
Cafuçus & $\begin{array}{l}\text { Bay discreto } \\
\text { Ursos }\end{array}$ & $\begin{array}{c}\text { Gay afeminado } \\
\text { 'Tia' } \\
\text { Machudo (pai de família) }\end{array}$ \\
\hline+
\end{tabular}

Fonte: Adaptado de Perlongher (2008, p. 157) 
por tentar alavancar as do próprio sujeito. Nesse extremo aparecem homossexuais afetados, velhos (tias), ou com condutas que não são recebidas como aceitáveis para um homem (travestis).

Observa-se, assim, que as 'identidades' são manuseadas como parte constitutiva do jogo das trocas que a pegação no cinema suscita. São fixas e simultaneamente fluídas, a mercê dos interesses dos próprios usuários. No entanto, é necessário averiguar, ainda, a existência de um mecanismo micro, que permite ao sujeito flexibilizar, por exemplo, sua performance para ser identificado como um gay discreto, ainda que em outros lugares não seja; esse mecanismo micro ocorre com um mecanismo macro, conformado pelo tecido social daquele espaço, que tem o poder de acatar ou rejeitar tal flexibilidade, a exemplo de uma história narrada por Francisco a respeito de um encontro que teve com um senhor que se dizia discreto, mas que, ao encontrá-lo de pronto, sentiu-se enganado ao encontrar com um homem mais velho que ele e também mais afeminado, enfim, uma 'tia'. Dessa forma, acreditamos que pensar a identidade nesses espaços como constituição fixa é enganador, ou, pelo menos, limitador; se são fixas, são apenas durante os breves minutos dos encontros efêmeros que desenvolvem, sendo em seguida reconstituídos em outras formas de ser e estar que podem afirmar, negar ou ocultar as práticas anteriores. Sugerimos, assim, a existência de 'estratégia identitárias', dispositivos de diferenciação e reconhecimento acionados à medida das circunstâncias tão somente.

\section{Considerações Finais}

As performances que acompanho, têm como propósito, favorecer o sucesso das interações dos sujeitos em busca de encontros corporais em um cinema pornô da cidade de
João Pessoa. No que nos toca, tais performances são possibilidades acionadas à mercê da natureza e dos interesses envolvidos em cada interação dos sujeitos uns com os outros.

Em termos gerais, a masculinidade é um mecanismo valorizado e evidenciado pelos sujeitos na busca de parceiros; assim, elementos corporais importantes para a conformação de tais performances, a exemplo da postura ao movimentar-se, da voz, a exposição ou insinuação do uso do pênis ou do ânus, além de demais formas de usar o corpo, são importantes na medida em que indicam pistas, caminhos e possibilidades para as práticas sexuais ou eróticas a serem desenvolvidas.

A valorização da masculinidade é acompanhada por um dispositivo recorrente de negação, de um modelo socialmente construído de homossexualidade como valoração negativa, de base feminina, e que tais sujeitos não compartilham ou rejeitam, razão pela qual reinventam, negam ou ocultam formas de identidade consolidadas pelas políticas de visibilidade, estabelecidas pelo movimento LGBT nos últimos 40 anos no Brasil. Nesse processo, é preciso, ainda, advertir para uma característica importante de que a afirmação de tal masculinidade é feita em detrimento da desvalorização de certas performances ou identidade sexuais relacionadas a uma esfera mais feminina.

1 Todos os nomes aqui são fictícios e foram escolhidos pelos próprios interlocutores durante a escrita e leitura desse artigo.

2 Exceção seja feita aqui ao trabalho de Parker (1982), que desenvolveu sua pesquisa sobre homoerotismo, homossexualidade em São Paulo (SP) e Belém (PA). 
3

Tradução do autor.

4 Mancha' aqui é entendida a partir da definição de Magnani, para quem "são manchas áreas contíguas do espaço urbano dotadas de equipamentos que marcam seus limites e viabilizam - cada qual com sua especificidade, competindo ou complementando uma atividade ou prática dominante" (1996, p. 40).

5 Menage a trois, ou como falam os frequentadores do cinema, "suruba", é como se chamam as relações sexuais entre três parceiros, podendo envolver diversos arranjos não heterossexuais, tais como unicamente homossexuais, unicamente heterossexual, bissexuais, travestis e homossexuais, travestis e heterossexuais, enfim.

6 Semelhante aos casos etnografados por Gaspar Neto (2011), nos cinemas onde desenvolvemos a pesquisa não é comum o sexo anal público; há algumas modalidades sexuais que podem acorrer à vista de todos, como o sexo oral e a masturbação individual e recíproca. Em geral a razão para tais proibições está localizada numa lógica própria de etiqueta pautada na discrição dos atos e preservação das identidades fora daquele lugar.

7 O uso da variante fonética "viado" em vez de "veado" é intencional

8 Para uma análise mais aprofundada sobre a presença de travestis em espaços de sociabilidade marcadas pela pegação ver Vale (2000) que apresenta uma etnografia do cine Jangada, em Fortaleza, evidenciando a presença de travestis que ali se prostituem. Tais processos de prostituição travesti, ou mesmo de frequência destas personagens não foram observados durante o campo, exceto por uma situação onde uma conhecida travesti da cidade apareceu lá, mas neste caso especial, estava "desmontada" ou seja, construiu para si um corpo e uma performance masculinos.

9 Travesti aqui recebe uma significação diferente, não referindo-se necessariamente a uma identidade sexual travesti; antes, refere-se a tudo aquilo que é visto como um extremo 'não-homem', não masculino, sem tampouco ser feminino. Para todos os fins, É uma marca de ambiguidade tomada como jocosa, e por vezes, que deve ser evitada.

\section{Referências}

AGIER, Michel. Antropologia da cidade: lugares, situações, movimentos. São Paulo: Terceiro nome, 2011.

BUTLER, Judith. Problemas de Gênero: feminismo e subversão da identidade. Tradução de Renato Aguiar. São Paulo: Civilização Brasileira, 2003.

CONNELL, Raewyn. Masculinities. $2^{\circ}$ edição. Berkeley: University of California Press, 2005.

DUARTE, Luis Fernando Dias. A Sexualidade nas Ciências Sociais: leitura crítica das convenções. In: PISCITELLI, Adriana; GREGORI, Maria Filomena; CARRARA, Sérgio. Sexualidades e saberes: convenções e fronteiras. Rio de Janeiro: Garamond, 2005, p. 39 - 80

FACCHINI, Regina: Sopa de letrinhas: movimento homossexual e produção de identidades coletivas nos anos 90. Rio de Janeiro: Garamond, 2005.

FRY, Peter. Pra inglês ver: identidade e política na cultura brasileira. Rio de Janeiro: Zahar, 1982.

FONSECA, Claudia. A morte do gigolô: fronteiras da transgressão e sexualidade nos dias atuais". In: PISCITELLI, Adriana; GREGORI, Maria Filomena; CARRARA, Sérgio. Sexualidades e saberes: convenções e fronteiras. Rio de Janeiro: Garamond, 2005, p. 257 - 282.

FOUCAULT, Michel. História da Sexualidade - a vontade de saber. Rio de Janeiro: Graal, 1999.

FREHSE, Fraya. Usos da cidade. In: 
FORTUNA, Carlos; LEITE, Rogério Proença. Plural de Cidade: novos léxicos urbanos. Lisboa: Almedina, 2009, p. 151 170.

GASPAR NETO, Verlan Valle. A Organização da transgressão em espaços de pegação masculina: três breves relatos etnográficos". Antropolítica, n. 15, v. 2, n. 15, p. 147-165, 2011.

HUBBARD, Phil. Cities and Sexualities. Nova York: Routledge, 2012.

LEITE JÚNIOR, Jorge. Das Maravilhas e prodígios sexuais: a pornografia bizarra como entretenimento. São Paulo: FAPESP/ Annablume, 2006.

LÉVI-STRAUSS, Claude. Estruturas Elementares do Parentesco. Tradução de Mariano Ferreira. São Paulo: Vozes, 2012 [1967].

MACRAE, Edward. A Construção da igualdade: identidade sexual e política no Brasil da abertura. Campinas: Unicamp, 1990.

MAGNANI, José Guilherme Cantor. Quando o campo é a cidade: fazendo antropologia na metrópole. in: MAGNANI, José Guilherme Cantor.; TORRES, Lilian DeLucca. Na Metrópole: textos de antropologia urbana. São Paulo: FAPESP / EDUSP, 1996, p. 12 53.

MAUSS, Marcel. Sociologia e Antropologia. São Paulo: Cosac Naify, 2003.

PARKER, Robert. A Cidade: sugestões para a investigação do comportamento social no meio urbano. In: VELHO, Otávio Guilherme. O Fenômeno Urbano. $2^{\circ}$ edição. Rio de
Janeiro: Zahar, 1973, p. 25 - 66.

PERLONGHER, Néstor. O Negócio do michê: a prostituição viril em São Paulo. São Paulo: Perseu Abramo, 2008.

VALE, Alexandre Fleming Câmara. No Escurinho do cinema: cenas de um público implícito. São Paulo/ Fortaleza: Annablume/ Governo do Estado do Ceará, 2000.
Recebido em 18 de fevereiro de 2014. Aceito em 05 de outubro de 2014. 